centration at the beginning of treatment and a further rise once the haemoglobin depletion had been corrected. The serum ferritin concentration was maintained after treatment had been discontinued and the values found in all groups corresponded to those in normal people.

Our data support the view that oral treatment should be continued for two months after the haemoglobin concentration has reached normal levels to replete iron stores. More-prolonged administration of iron is not indicated. Though high serum ferritin concentrations were found in some patients treated by total-dose infusion of iron dextran the results with oral ferrous sulphate were similar, suggesting that parenteral therapy has no special advantage.

We thank Abbott Laboratories for their support.

\section{Reference}

${ }^{1}$ De Gruchy, G. C., Clinical Haematology in Medical Practice, p. 104. Oxford, Blackwell, 1970.

2 Callender, S. T., in Iron in Biochemistry and Medicine, ed. A. Jacobs and M. Worwood, p. 535. London, Academic Press, 1974.

3 Jacobs, A., et al., British Medical fournal, 1972, 4, 206.

4 Young, D. S., and Hicks, J. M., fournal of Clinical Pathology, 1965, 18, 98.

${ }^{5}$ Addison, G. M., et al., fournal of Clinical Pathology, 1972, 25, 326.

${ }^{6}$ Lipschitz, D. A., et al., New England fournal of Medicine, 1974, 290, 1213.

${ }^{7}$ McCurdy, P. R., Fournal of the American Medical Association, 1965, 191, 859.

${ }^{8}$ Beutler, E., Drennan, W., and Block, M., Fournal of Laboratory and Clinical Medicine, 1954, 43, 427 .

${ }^{9}$ Bentley, D. P., and Williams, P., fournal of Clinical Pathology, 1974, 27,

${ }^{10}$ Harrison, P. M., et al., in Iron in Biochemistry and Medicine, ed. A. Jacobs and $M$. Worwood, p. 98. London, Academic Press, 1974.

11 Siimes, M. A., Addiego, J. E., and Dallman, P. R., Blood, 1974, 43, 581.

\title{
Peripheral Neuropathy and Indomethacin
}

\author{
O. E. EADE, \\ E. D. ACHESON, \\ M. F. CUTHBERT, \\ C. H. HAWKES
}

British Medical fournal, 1975, 2, 66-67

\section{Case 1}

\section{Summary}

A patient with seronegative inflammatory polyarthritis developed a predominantly motor peripheral neuropathy associated with the use of indomethacin. Three other cases of peripheral neuropathy associated with indomethacin treatment have been reported to the Committee on Safety of Medicines. In all cases the neuropathy regressed when indomethacin was stopped. Peripheral neuropathy should be recognized as a rare complication of indomethacin therapy and considered in the differential diagnosis of a neuropathy accompanying rheumatoid arthritis.

\section{Introduction}

Peripheral neuropathy is a well-recognized complication of rheumatoid arthritis, ${ }^{1-3}$ and the following types of neuropathy have been described: ( $a$ ) entrapment neuropathies; $(b)$ distal sensory neuropathy, with a generally good prognosis; (c) mononeuritis multiplex with a variable prognosis, often forming part of a generalized vasculitis with a picture resembling polyarteritis nodosa; and $(d)$ a severe distal sensorimotor neuropathy which may follow a mononeuritis multiplex and is characterized by symmetrical distal weakness, muscle wasting, and sensory impairment in all limbs. This last type carries a poor prognosis and may be due to vasculitis of the vasa nervorum ${ }^{4-6}$ or segmental demyelination. ${ }^{7}$ Some cases of severe neuropathy seem to be associated with the use of corticosteroids, but we have found no report of indomethacin being suspected as a causative factor.

\section{Royal South Hants Hospital, Southampton SO9 4PE}

O. E. EADE, M.B., M.R.C.P., Research Fellow in Medicine

E. D. ACHESON, D.M., F.R.C.P., Professor of Clinical Epidemiology

Committee on Safety of Medicines, London EC2 1PP

M. F. CUTHBERT, M.B., PH.D., Senior Medical Officer (Present appointment: Principal Medical Officer, Department of Health and Social Security, London EC2 IPP)

Wessex Neurological Centre, Southampton General Hospital, Southampton

C. H. HAWKES, M.D., M.R.C.P., Senior Registrar in Neurology

In June 1972 a 70 -year-old man developed arthritis in the right knee, which later spread to most joints with accompanying morning stiffness. He was treated with salicylates, ibuprofen, and Panadeine Co without improvement. In December the ibuprofen was discontinued and he was started on indomethacin $75 \mathrm{mg} /$ day, which was increased to $150 \mathrm{mg} /$ day. He was receiving frusemide for ankle oedema, and benorylate was added to the regimen on 30 December. His joint symptoms improved, but towards the end of May he noticed increasing weakness and unsteadiness of his legs with paraesthesiae in the hands and feet. The weakness progressed slowly until he was unable to climb stairs and needed support in walking. On admission to hospital on 5 July 1973 there was ulnar deviation and spindling of the fingers with restricted movement of both wrists. Other joints were inactive and there were no rheumatoid nodules. There was no abnormality of the cranial nerves. Power and tone were normal in the arms, but in the legs there was definite impairment of power, which was prominent in distal muscle groups. The right triceps jerk was just elicitable but all other tendon jerks were absent. There was no detectable sensory loss. Plantar responses were flexor and his gait was high-stepping. Nerve conduction studies confirmed slowing of motor conduction with normal sensory latencies (see table).

Results of Nerve Conduction Studies on Admission to Hospital and After Recovery of Patient in Case 1

\begin{tabular}{|c|c|c|c|c|}
\hline & \multicolumn{2}{|c|}{ July 1973} & \multicolumn{2}{|c|}{ June 1974} \\
\hline & $\begin{array}{l}\text { Wrist/Ankle } \\
\text { Latency } \\
\text { (ms) }\end{array}$ & $\begin{array}{c}\text { Forearm/Leg } \\
\text { Velocity } \\
(\mathrm{m} / \mathrm{s})\end{array}$ & $\begin{array}{c}\text { Wrist/Ankle } \\
\text { Latency } \\
(\mathrm{ms})\end{array}$ & $\begin{array}{c}\text { Forearm/Leg } \\
\text { Velocity } \\
(\mathrm{m} / \mathrm{s})\end{array}$ \\
\hline $\begin{array}{l}\text { Left common peroneal } \\
\text { Right median }\left\{\begin{array}{l}\text { motor } \\
\text { sensory } \\
\text { motor } \\
\text { sensory }\end{array}\right. \\
\text { Right ulnar }\end{array}$ & $\begin{array}{l}5 \cdot 5 \\
3 \cdot 2 \\
2 \cdot 5 \\
2 \cdot 6 \\
2 \cdot 5\end{array}$ & $\frac{27}{32}$ & $\begin{array}{l}5 \cdot 9 \\
3 \cdot 8 \\
2 \cdot 6 \\
3 \cdot 1 \\
2 \cdot 6\end{array}$ & $\begin{array}{l}39 \\
48 \\
51\end{array}$ \\
\hline
\end{tabular}

Investigations did not show any underlying cause for his neuropathy; in particular, we found no evidence of a neoplasm. The progress of the illness was unlike a Guillain-Barré syndrome, and the fact that he was negative for rheumatoid factor was unusual for a rheumatoid neuropathy of this severity. The possibility of a druginduced peripheral neuropathy was considered. Three cases of neuropathy in association with the use of indomethacin had previously been reported to the Committee on Safety of Medicines, so indomethacin was discontinued on 17 July 1973 and replaced by phenylbutazone suppositories. Benorylate had been discontinued on admission and he continued on frusemide for his ankle oedema. Before stopping indomethacin he had continued to deteriorate, but by 21 July he began to show some improvement in his walking. The paraesthesiae 
in his toes disappeared and by the end of July he had increased power in moving his toes. In August he was able to dorsiflex both feet and by the time of his discharge in mid-August he could walk with the aid of a walking stick. The improvement was maintained, and after four months his walking had returned to normal, though the ankle jerks remained absent. Repeat nerve conduction studies showed improvement in conduction velocities in all limbs (see table).

\section{Case 2}

A 60-year-old woman with muscle pains was treated with phenylbutazone for three weeks then changed to indomethacin $25 \mathrm{mg} /$ day. Two days later she noticed paraesthesiae in the fingers and after five days had developed peripheral muscle weakness. Examination two weeks later showed signs of a peripheral neuropathy. Her blood count, erythrocyte sedimentation rate, and cerebrospinal fluid protein were normal. Indomethacin was discontinued together with bendrofluazide and pentaerythritol tetranitrate which she had also been taking for one and two weeks respectively. She made a complete recovery over two months.

\section{Case 3}

A 53-year-old woman suffering from osteoarthrosis of the hips and knees received indomethacin $75 \mathrm{mg} /$ day increasing to $100 \mathrm{mg}$ after one week for five weeks before the onset of paraesthesiae in the hands. Paraesthesiae became severe and the dose of indomethacin was reduced after two weeks to $75 \mathrm{mg} /$ day. Over the next four months she became progressively more clumsy. Her grip was weak and light touch sensation of the fingertips was impaired. Six months after starting indomethacin the drug was stopped and one month later she made a complete recovery.

\section{Case 4}

A 75-year-old man was treated with aspirin and indomethacin for a seronegative inflammatory polyarthritis. The joint symptoms improved, but some weeks after starting treatment he developed numbness and paraesthesiae in the feet, which progressed to weakness of the legs and ataxia. On admission on 10 October 1967 he had distal muscle weakness of the legs with a stocking distribution of sensory loss. All drugs were stopped on admission to hospital and rheumatoid neuropathy was diagnosed. He was discharged on 22 October taking indomethacin $75 \mathrm{mg} /$ day and was readmitted on 16 November with a severe peripheral neuropathy. The possibility of the neuropathy being caused by indomethacin was considered, the drug was discontinued, and he was started on prednisolone $20 \mathrm{mg} /$ day and Parentrovite. He made a steady improvement, reaching full recovery over four months; steroids were continued during this period.

\section{Discussion}

Patients with rheumatoid arthritis who develop peripheral neuropathy other than entrapment neuropathies show a high incidence of nodule formation, 58 and seropositivity for the rheumatoid factor is almost invariable with the more severe motor neuropathy..$^{5} 9$ This type of neuropathy is generally associated with classical rheumatoid arthritis accompanied by severe disability, and evidence of vasculitis is commonly found - for example, nailfold lesions, leg ulcers, and episcleritis. ${ }^{8}$ The relation of rheumatoid neuropathy to corticosteroid treatment has been discussed $;^{3}$ s $^{1-14}$ most patients with neuropathy, particularly of the severe motor type, have received steroids, ${ }^{15}$ but the association may have been partly due to the past tendency to use steroids in the more severe cases of arthritis. In one series $^{8}$ no therapeutic association apart from steroids was found.

We believe that the condition in case 1 differed from rheumatoid neuropathy in several respects: the joint disease was mild, there was no nodule formation or evidence of vasculitis, and the rheumatoid factor was absent. The neuropathy was mainly motor, it affected the legs predominantly, with paraesthesiae in the hands and feet as the only sensory manifestations, and the patient had never received corticosteroids. These differences favour some other aetiological factor. The fact that he continued to deteriorate before indomethacin was stopped but started to improve shortly afterwards strongly suggests that indomethacin was a causative factor.

The patients in cases 2 and 3 did not seem to have rheumatoid arthritis, and both recovered when indomethacin was withdrawn. Indomethacin was possibly not the cause of symptoms in case 2 because of their early onset, but it might have been. The patient in case 4 resembled that in case 1 , and his further deterioration seemed to coincide with the reintroduction of indomethacin after his initial discharge from hospital. Attributing his recovery to indomethacin withdrawal, however, is complicated by the additional treatment with prednisolone and Parentrovite. Two other patients, a 78-year-old woman with osteoarthritis and a 55-year-old woman with rheumatoid arthritis, have been reported to the Committee on Safety of Medicines, but details are lacking. Both patients developed sensory symptoms in the hands, which regressed on withdrawal of indomethacin.

Though other factors may have been involved in the aetiology of peripheral neuropathy in these patients indomethacin was probably a factor in most if not all the cases. It is therefore important to be aware of this possibility in the differential diagnosis of a peripheral neuropathy in patients treated with indomethacin. In all cases the neuropathy regressed when treatment with indomethacin was stopped.

We thank Professor Sir Eric Scowen and Professor Sir Richard Doll for permission to publish data reported to the Committee on Safety of Medicines. We thank also the doctors who provided additional information on patients under their care and gave permission for it to be included in this paper.

\section{References}

1 Hart, F. D., Golding, J. R., and MacKenzie, D. H., Annals of the Rheumatic Diseases, 1957, 16, 471.

${ }^{2}$ Hart, F. D., and Golding, J. R., British Medical fournal, 1960, 1, 1594

3 Steinberg, V. L., British Medical fournal, 1960, 1, 1600 .

4 Kemper, J. W., Baggenstoss, A. H., and Slocumb, C. H., Annals of Internal Medicine, 1957, 46, 831 .

5 Pallis, C. A., and Scott, J. T., British Medical fournal, 1965, 1, 1141.

- Weller, R. O., Bruckner, F. E., and Chamberlain, M. A., Fournal of Neurology, Neurosurgery and Psychiatry, 1970, 33, 592.

7 Beckett, V. L., and Dinn, J. J., Quarterly Journal of Medicine, 1972, 41, 71.

8 Chamberlain, M. A., and Bruckner, F. E., Annals of the Rheumatic Diseases, 1970, 29, 609 .

Diseases, 1970, 29,609.
Ansell, B., Proceedings of the Royal jociety of Medicine, 1960, 53, 49.

10 Ferguson, R. H., and Slocumb, C. H., Bulletin on Rheumatic Diseases, $1961,11,251$.

11 Vignon, G., Durant, J., and Tissot-Guerraz, R., Semaine des Hôpitaux de Paris, 1970, 46, 3351 .

12 Golding, J. R., British Medical fournal, 1971, 2, 169.

is Golding, D. N., British Medical fournal, 1971, 2, 169.

14 Meienberg, O., et al., Deutsch medizinische Wochenschrift, 1972, 97, 1595.

15 Scott, J. T., Textbook of Rheumatic Diseases, ed. W. S. C. Copeman, 4th edn., p. 643. Edinburgh and London, Livingstone, 1969. 